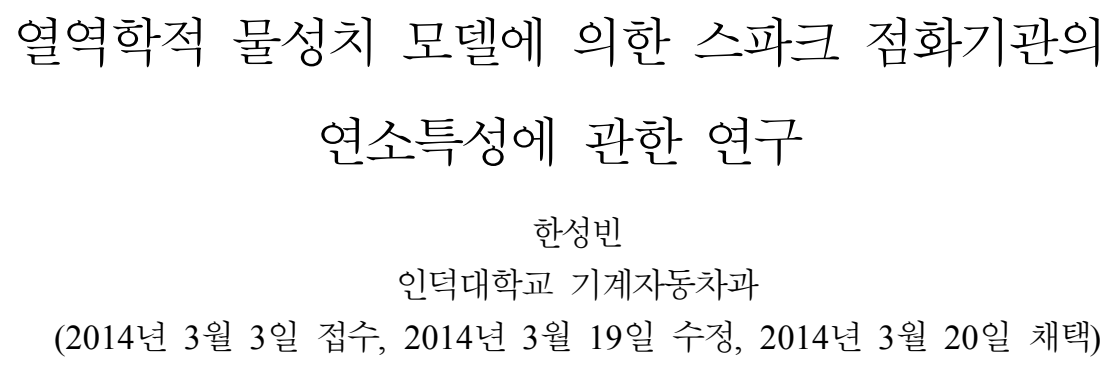

\title{
A Study on the Combustion Characteristics of Spark Ignition Engine by the Thermodynamic Properties Model
}

\author{
Sung Bin Han \\ Department of Mechanical \& Automotive Engineering, Induk University \\ (Received 3 March 2014, Revised 19 March 2014, Accepted 20 March 2014) \\ 요 약 \\ 지난 최근 몇 년 동안 내연기관 엔진의 여러 가지 타입의 성능, 효율, 배기가스 특성을 잘 설명해 \\ 줄 수 있는 흥미있는 수학적인 모델이 다양하게 제시되고 있다. 이러한 다양한 양상의 엔진 작동의 \\ 모의실험에 있어서 주요한 요소가 엔진 연소 과정의 모델이다. 연소모델은 주로 세 가지 분류로 세분화 \\ 즉, 제로 차원적, 유사 차원적, 다차원 모델로 나눌 수 있다. 제로 차원모델은 열역학 제 1 법칙에 근거 \\ 하여 만들어졌고, 시간은 단지 독립 변수이다. 본 연구는 제로 차원 모델에 의하여 스파크 점화 기관의 \\ 연소 특성을 제시하려는 그 목적이 있다. \\ 주요어 : 열역학적 모델, 물성치, 제로 차원 모델, 스파크 점화 기관, 수소, 연소특성

\begin{abstract}
- he past several years have seen a substantial growth in mathematical modeling activities whose interests are to describe the performance, efficiency and emissions characteristics of various types of internal combustion engines. The key element in these simulations of various aspects of engine operation is the model of the engine combustion process. Combustion models are then classified into three categories: zero-dimensional, quasi-dimensional and multidimensional models. zero-dimensional models are built around the first law of thermodynamics, and time is the only independent variable. This paper presents a introduction to the combustion characteristics of a spark ignition combustion modeling by zero-dimensional model.
\end{abstract} 되어지고 있다.

Key words : Thermodynamic model, Properties, one-dimensional model, spark ignition engine, hydrogen, combustion characteristics

\section{1. 서 론}

\footnotetext{
${ }^{\dagger}$ To whom corresponding should be addressed. Department of Mechanical \& Automotive Engineering, Induk University, 12 Choansan-ro, Nowon-gu, Seoul 139-749, Korea. Tel : 02-950-7545 E-mail : sungbinhan@induk.ac.kr
}

유용한 에너지를 비교적 잘 사용하고 있는 자동차 는 인간에게 편리함을 제공하였으나, 자동차에서 배 출되는 유해한 배기가스는 날로 심각하며, 더욱이 최 근 강화된 배기가스 규제와 대체 에너지 개발의 문제 가 더욱 중요한 문제로 대두되고 있다. 특히 내연기 관용 자동차에서 일어나는 연소현상은 복잡한 현상이 
며, 이론적으로 이를 해석한다는 것은 참으로 힘든 작업이다. 이러한 어려운 문제를 해결하기 위해서는 타당한 가정을 바탕으로 해석 가능한 모델을 설정하 여 연소과정에 적용시키는 연소 모델 기법이 있다 [1-3]. 근래에 와서 여러 연구자들에 의하여 연소모델 을 설정하여 많은 발전을 하여 온 것이 사실이다. 하 지만 이러한 모델링 기법은 대개가 스파크 점화기관 이나 압축점화기관을 기본으로 하고 있어서 대체 에 너지 측면에서 가장 활용도가 크다고 할 수 있는 수 소기관에 적용시키기는 어려운 점이 있다 [4-6]. 수 소연료를 사용하는 스파크 점화기관에서 해석할 수 있는 단순화된 모델 기법이 절실히 요구되며, 본 연 구의 목적도 단순하면서도 이용가치가 있는 모델을 연구하는데 있다.

J. B. Heywood $[7,8]$ 는 열역학 모델을 설정하여 미연 혼합물 및 기연가스의 온도, 압력 등을 구하였 다. 이러한 동력 사이클에 대한 모델과 함께 연소가 스의 열역학적 성질과 조성변화에 대해서도 많은 연 구가 수행되고 있는 것이 사실이다.

연소과정에 대한 모델은 일반적으로 zero dimensional 모델, quasi - dimensional (entrainment) 모델, multidimensional (detailed) 모델 등으로 구분 짖는다. 특히 열역학적 모델은 열역학 제 1 법칙을 기 초로 하여 만들어졌고, 이는 시간만이 독립변수이다. 또한 entrainment 모델은 실린더 내의 혼합기의 층류 연소속도, 난류 특성 등의 기초적인 양을 이용하여 화염전파 및 적당한 화염구조 등을 가정하여 질량 연 소율을 구할 수 있다. 그리고 다차원 모델은 연소영 역을 공간적으로 분할하여 각 지점에서의 질량, 운동 량, 에너지 및 성분 화학종의 비정상 보존 방정식과 상태식, 난류모델, 연소모델, 기타의 모델의 수치계산 으로 해를 얻으며, 연소실 내의 가스유속, 온도, 성분 농도의 공간적 분포에 관한 해도 얻을 수 있다.

연소예측은 열역학적 사이클의 계산 수행의 영향 으로 기관작동변수의 영향을 결정할 수 있는 편리성 을 제공하며, 아울러 내연기관의 연소과정에 있어서 발생하는 여러 문제점을 예측할 수 있을 것으로 생각 된다 [9-11].

따라서 본 연구에서는 수소연료를 이용한 스파크 점화기관에서 해석할 수 있는 연소모델을 연구하고 이를 이용하여 간단한 연소예측을 하는데 있다. 본 연구에서는 초기 단계로써 타당한 열역학적 물성치 $[12,13]$ 에 대한 연구를 수행하려 한다.

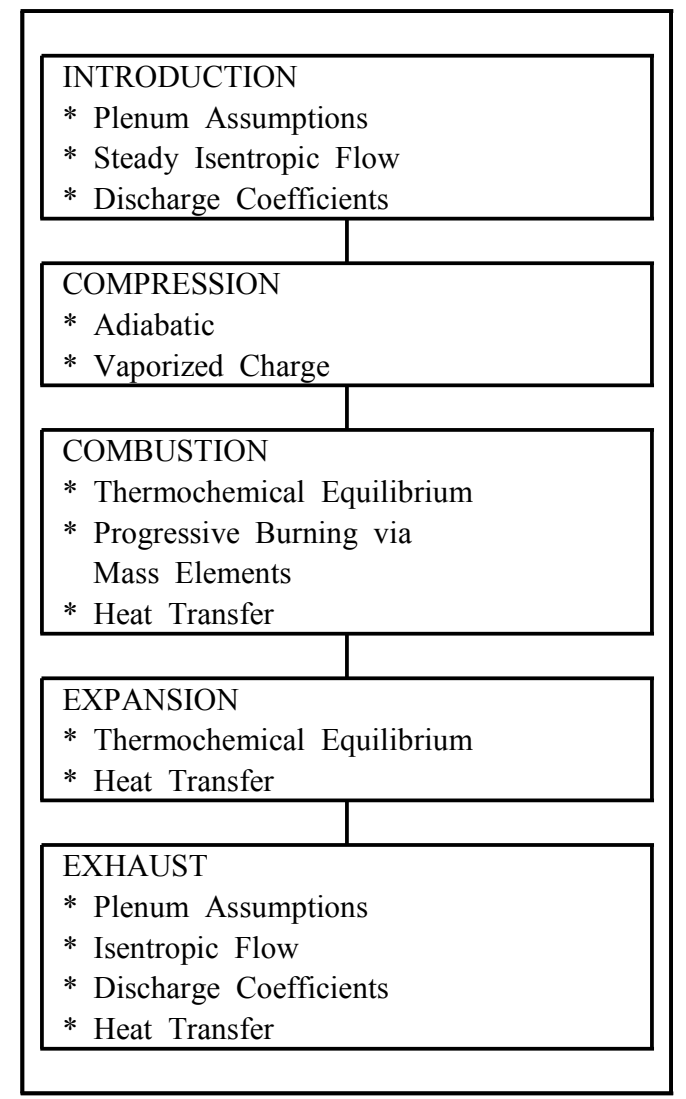

Fig. 1. Block diagram of zero-dimensional model.

\section{2. 연소모델 결정}

본 연구를 수소 스파크 점화기관을 위한 연소모델 의 기초 단계로 zero-dimensional 모델을 이용한다. zero-dimensional 모델은 간단하면서, 수소연료의 각 종 열역학적 상태량을 파악할 수 있는 장점을 가지고 있다. Fig.1은 zero-dimensional 모델의 진행방향이며, 본 연구에서는 연소영역 만을 채택하여 해석하고자 한다. zero-dimensional 연소현상의 모델화를 위하여 서 다음과 같은 가정이 필요하다 [9-11].

가정 :

(1) 연소실은 unburned 와 burned gas zone의 두 영역으로 나눈다.

(2) 각 영역에서 열역학적 상태량은 균질하다.

(3) 연소실 내의 압력은 공간적으로는 균일하다.

(4) 연소실 벽과의 열 교환이 무시된다.

(5) 연소가스의 각 요소가 독립으로 압축되어, 상호 확산이나 혼합이 행하여지지 않는다. 


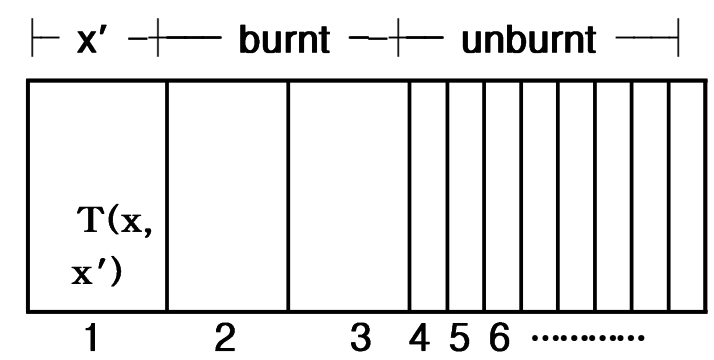

Fig. 2. Combustion chamber configuration for zero-dimensional model.

연소해석을 위해서 Fig.2와 같이 연소실을 단순화 시킨다. 단순화한 연소실에서 혼합기가 연소하는 과 정를 모델화하기 위하여 혼합기를 다수의 미소부분 $1,2,3, \cdots \cdots$ 등으로 분할하여, 1 의 부분이 연소한 직 후에 그 팽창에 의하여 그 이하의 미연소부분이 압축 되고, 다시 2 의 부분이 연소한 직후에는 3 이하가 다 시 압축을 받음과 동시에 1 도 압축되고, 이와 같은 방법으로 화염이 전파되는 경우에, 연소실 내 가스의 에너지 균형은 열역학 제 1 법칙으로부터,

$$
M \frac{d e_{T}}{d \theta}=\frac{d Q}{d \theta}-P \frac{d V}{d \theta}
$$

로 표현된다.

(1)식에서 $e_{T}$ (총 비 내부에너지)는 다음과 같다.

$e_{t}=x \bar{e}_{b}+(1-x) e_{u}$

$\bar{e}_{b}$ : 기연가스의 평균비 내부에너지

$e_{u}$ : 미연가스의 평균비 내부에너지

$x$ : 질량 연소율

또한, $e_{u}, \bar{e}_{b}$ 는

$$
\begin{gathered}
e_{u}=C_{v u} T_{u}+a_{u} \\
\bar{e}_{b}=C_{v b} T_{b}+a_{b}
\end{gathered}
$$

$a_{w}, a_{b}$; 미연(기연)가스의 절대 0 도에서의 형성 엔탈피 $(\mathrm{kJ} / \mathrm{kg})$

Fig.2에서 질량연소율 $\mathrm{x}$ 의 시점에서 먼저 연소한 $\mathrm{x}^{\prime}$ 부분의 가스온도를 $\mathrm{T}\left(\mathrm{x}, \mathrm{x}^{\prime}\right)$ 라 하면 연소가스의 평균 온도 $\bar{T}_{b}(x)$ 는 (5)식과 같이 표현되며,

$$
\bar{T}_{b}(x)=\frac{1}{x} \int_{0}^{x} T_{b}\left(x, x^{\prime}\right) d x
$$

이므로, $\bar{e}_{b}(\mathrm{x})$ 는 (6)식과 같이 표현된다.

$$
\begin{aligned}
\bar{e}_{b}(x)= & \frac{1}{x} \int_{0}^{x}\left[C_{v_{b}} T_{b}\right. \\
& \left.\left(x, x^{\prime}\right)+a_{b}\right] d x^{\prime}
\end{aligned}
$$

또한 미연혼합기는 균일하다고 하고, 등엔트로피 압축으로 가정하면 연소시작 때의 혼합기의 상태는 다음과 같다.

$$
\begin{aligned}
& P_{o}=P_{m}\left[V_{i} / V\left(\theta_{o}\right)\right]^{k_{u}} \\
& T_{u}=T_{u o}\left(P / P_{o}\right)^{\left(k_{u}-1\right) / k_{u}}
\end{aligned}
$$

$P_{m}$ : 흡기관 압력

$P_{o}, T_{u o}$ : 점화시의 압력 및 온도

$V_{i}:$ 압축시작의 체적

$V\left(\Theta_{o}\right): \Theta_{o}$ 에서의 실린더 체적

또한 (1)식에 (2)식을 대입하면,

$$
\begin{aligned}
& M \cdot\left\{\begin{array}{l}
x \cdot \frac{d \bar{e}_{b}}{d \theta}+(1-x) \frac{d e_{u}}{d \theta}+ \\
\left(\bar{e}_{u}-e_{u}\right) \frac{d x}{d \theta}
\end{array}\right\} \\
& =\frac{d Q}{d \theta}-P \cdot \frac{d V}{d \theta}
\end{aligned}
$$

또한, $V_{b}+V_{u}=V$ 의 관계로부터,

$$
\frac{M \cdot x R_{b} \bar{T}_{b}}{P}+\frac{M \cdot(1-x) R_{u} \bar{T}_{u}}{P}=V
$$

또한

$$
\frac{d Q}{d \theta}=P \frac{d V}{d \theta}\left(1+\frac{C_{v b}}{R_{b}}\right)+\frac{C_{v b}}{R_{b}} \cdot V \frac{d P}{d \theta}
$$


로 나타내고, 질량 연소율 $\mathrm{x}$ 는 Wiebe function을 이용하여 다음과 같이 표현된다.

$$
\begin{aligned}
& x=1-\operatorname{Exp}\left[-a\left\{\left(\theta-\theta_{o}\right) / \Delta \theta_{b}\right\}^{m+1}\right] \\
& a, m: \text { 상수 } \\
& \Theta_{o}: \text { 연소 시작점 } \\
& \Delta \Theta_{b}: \text { 연소기간 } \\
& \frac{d x}{d \theta}=\frac{(m+1) a}{\theta_{b}{ }^{m+1}} \cdot\left(\theta-\theta_{o}\right)^{m} \cdot \\
& \operatorname{Exp}\left\{-a\left(\frac{\theta-\theta_{o}}{\theta_{b}}\right)^{m+1}\right\} \\
& \frac{M \cdot x R_{b} \bar{T}_{b}}{P}+\frac{M \cdot(1-x) R_{u} \bar{T}_{u}}{P}=V
\end{aligned}
$$

또한 연소실 체적 $\quad V(\Theta)$ 는 (14)식과 같으며,

$$
V(\theta)=V_{c}+\frac{\pi}{4} D^{2} r\left\{\begin{array}{l}
(1-\cos \theta)+ \\
\frac{1}{4 \lambda}(1-\cos 2 \theta)
\end{array}\right\}
$$

$V_{c}$ : 연소실 체적

$D$ : Bore

$r$ : crank radius

$\lambda: l / r$

$l$ : 커넥팅 로드의 길이.

(14)를 미분하면

$$
\frac{d V}{d \theta}=\frac{\pi}{4} D^{2} r\left(\sin \theta+\frac{1}{2 \lambda} \sin 2 \theta\right)
$$

또한, 기연가스의 온도는 연소실을 분할하여 각 element의 연소 전후의 엔탈피가 같다고 하여 온도를 구한다.

$$
\begin{aligned}
h_{b}=e_{b}+R T_{b} & =\left(C_{v b}+R_{b}\right) T_{b}+a_{b} \\
& =C_{P b} T_{b}+a_{b}
\end{aligned}
$$

$$
\begin{aligned}
& h_{b}=h_{u} \text { 이므로 } \\
& C_{P b} T_{b}+a_{b}=C_{P u} T_{u}+a_{u} \text { 에서 }
\end{aligned}
$$

$$
T_{b}=\frac{C_{P u} T_{u}+\left(a_{u}-a_{b}\right)}{C_{P b}}
$$

따라서 질량연소율이 $x$ 일때, 그 시점에서 연소한 가스의 온도 $T_{b}(x, x)$ 및 최초에 연소한 $x^{\prime}$ 에서 의 온도 $T_{b}\left(x, x^{\prime}\right)$ 는 (17)식에 (8)식을 대입하여,

$$
T_{b}(x, x)=\frac{C_{P u} T_{u o}\left(\frac{P(x)}{P_{o}}\right)^{\frac{k_{u}-1}{k_{u}}}+\left(a_{u}-a_{b}\right)}{C_{P b}}
$$

$$
T_{b}\left(x, x^{\prime}\right)=T_{b}(x, x) \cdot\left(\frac{P(x)}{P(x)}\right)^{\frac{k_{u}-1}{k_{u}}}
$$

위의 관계식으로부터 $x, V, P, \mathrm{~T}, T_{b}\left(x, x^{\prime}\right)$, $T_{b}(x, x), d Q / d \Theta$ 등을 구하려면 열역학적 물성 치를 정확히 알아야 해석이 가능하다.

\section{3. 수소 스파크 점화기관의 연소특성}

Fig.3은 앞에서 제시한 식을 이용하여 계산에 의하 여 구한 크랭크 각에 대한 압력선도이다. 본 연구에 서는 점화시기를 $-35^{\circ},-30^{\circ},-25^{\circ},-20^{\circ}$, 그리고 $-15^{\circ}$ 에서 한 것으로 가정하고 계산을 수행하였다. 계산

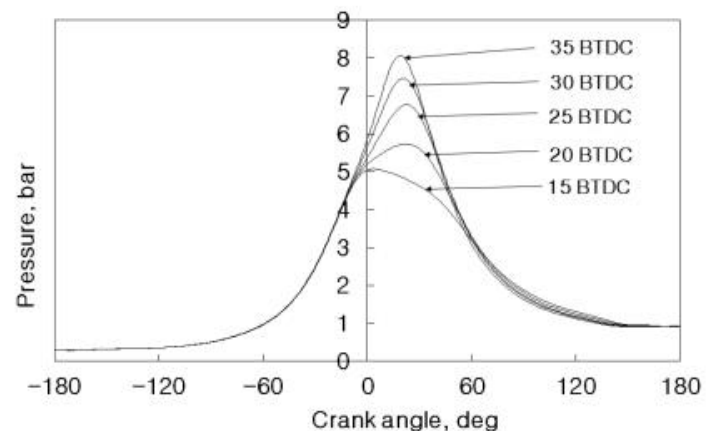

Fig. 3. Combustion chamber configuration for zero-dimensional model. 
Table 1. Calculation condition for combustion prediction.

\begin{tabular}{c|c}
\hline Items & Specification \\
\hline \hline Bore x Stroke & $76.9 \times 86 \mathrm{~mm}$ \\
\hline Displacement & $1598 \mathrm{cc}$ \\
\hline Compression ratio & 8.5 \\
\hline Connecting rod & $153.7 \mathrm{~mm}$ \\
\hline Engine speed & $1,800 \mathrm{rpm}$ \\
\hline Spark advance & $-35^{\circ} \sim 15^{\circ}$ (BTDC) \\
\hline Air fuel ratio & Stoichiometric mixture \\
\hline Mixture & Hydrogen and air \\
\hline
\end{tabular}

Table 2. Input data for the combustion prediction (35BTDC).

\begin{tabular}{c|c|c}
\hline$k_{u}$ & $k_{b}$ & $C_{v u}, \mathrm{~kJ} / \mathrm{kgK}$ \\
\hline 1.188 & 1.139 & 0.9526 \\
\hline$T_{u o}, \mathrm{~K}$ & $\theta_{o}, \mathrm{deg}$ & $P_{o}, \mathrm{kPa}$ \\
\hline 780 & -35 & 834 \\
\hline$M, \mathrm{~kg} / \mathrm{cycle}$ & $a$ & $a_{u}, \mathrm{~kJ} / \mathrm{kg}$ \\
\hline 0.0002684 & 10.1 & 1833 \\
\hline$C_{v b}, \mathrm{~kJ} / \mathrm{kgK}$ & $C_{p u}, \mathrm{~kJ} / \mathrm{kgK}$ & $C_{p b}, \mathrm{~kJ} / \mathrm{kgK}$ \\
\hline 1.3125 & 1.237 & 1.5141 \\
\hline$V_{o}, \mathrm{~m} 3$ & $\Delta \theta_{b}, \mathrm{deg}$ & \\
\hline 0.00011152 & 55 & \\
\hline$a_{b}, \mathrm{~kJ} / \mathrm{kg}$ & $m$ & \\
\hline-846 & 1.8 & \\
\hline
\end{tabular}

대상 기관은 4 개의 실린더를 가지고 있는 상용차를 대상으로 삼았고, 연소예측을 위한 계산 조건은 Table 1과 같다. Fig.3의 결과를 얻기 위하여는 기타 여러 열역학적 물성치를 알아야 한다. 연소예측으로 는 압력선도만 정확히 구할 수 있다면 기타의 열발생 율 선도, 질량연소율 곡선 등는 쉽게 구할 수 있다.

Table 2 는 점화시기 $-35^{\circ}$ 에서의 각종 열역학적 물 성치의 대표적인 값을 제시했다. 이런식으로 점화시 기 $-30^{\circ},-25^{\circ},-20^{\circ}$, 그리고 $-15^{\circ}$ 를 각각 열역학 물성 치를 구할 수 있다.

Fig.3으로부터 스파크 점화기관에서 점화시기를 앞 당기면 최고압력값의 위치가 빨라지고, 상사점 근처 에서 최고압력값이 나타난다. Fig.3에서 점화시기를 가장 앞당긴 $-35^{\circ}$ 인 경우가 통상적인 실제의 엔진 실 험결과에서 예측한 점화시기를 $-35^{\circ},-30^{\circ},-25^{\circ}$, $-20^{\circ}$, 그리고 $-15^{\circ}$ 중에서 가장 큰 최고 압력을 나타
내고 있으므로 이론적인 타당한 값을 나타내고 있음 을 보여 주고 있다. 하지만 점화시기를 지연시킨 $-15^{\circ}$ 의 경우는 예상 했듯이 가장 낮은 압력값을 나타내고 있다. 이러한 결과는 열역학적 이론식에 의한 연소예 측이며, 실제 수소기관에서 얻은 데이타와 비교해 보 아야 좀 더 그 타당성이 입증될 것이다.

\section{4. 결론}

스파크 점화기관 같이 빠른 연소과정 해석한다는 것은 어려운 과정이다. 그래서 가장 간단한 수소기관 을 대상으로, 단순 하면서도 이용가치가 있는 zerodimensional 모델을 선정하여 연구하였다.

(1) 모델은 단순하지만, 여기에 사용되는 열역학적 물성치 $k_{w}, k_{b}, C_{v w}, C_{v b}, C_{p w}, C_{p b}$, $T_{\text {uo }}, \Theta_{o}, P_{o}, V_{o}, \Delta \Theta_{b}, M, a, a_{w}$, $a_{b}, m$ 등을 정확히 구할 수 있다면 구지 다 차원모델이 아니어도 실험에 접근된 값을 구할 수 있다.

(2) 모델의 변수는 점화시기를 변화시켜 단계적으로 계산했다. 점화시기를 앞당기면 최고압력값의 위치가 빨라지고, 상사점 근처에서 최고압력값 이 나타냈다. 점화시기를 가장 늦게 지연시킨 $-15^{\circ}$ 의 경우는 예상 했듯이 가장 낮은 압력값 을 나타내고 있다.

(3) 아직은 정성적, 정량적으로 열역학적으로 부족 한 면이 많이 있다. 추후 좀 더 정확한 열역학 적 상태량을 보강할 필요가 있다.

\section{References}

1. Goodwin, A. R.; Sengers, J. V.; Peters, C. J., Applied Thermodynamics of Fluids, RSC Publishing, 2010

2. Anbarasu M.; Abata, D. L., Modeling of Early Pressure Rise and Flame Growth in a Spark Ignition Engine, 1994, SAE Paper No.941930

3. Pan, J.; Sheppard, C. G. W., A Theoretical and Experimental Study of the Modes of End Gas Autoignition Leading to Knock in S.I. Engine, 
1994, SAE Paper No.942060

4. Shi, Y.; Ge, H. W.; Reitz, R. D.,Computational Optimization of Internal Combustion Engines, Springer, 2010

5. Burstall, A. F., Experiments on the Behavior of Various Fuels in a High Speed Internal Combustion Engine, Proc. Inst. Automobile Engineerings 22, 1977, 358

6. Furuhama, S., LH2-Car Musahi-8 \& Development for 20 years, Proceedings of the Korea-Japan Joint Symposium '91 on Hydrogen energy, 1991, $1-21$

7. Heywood, J. B., Combustion Modelling in Reciprocating Engines (Engine Combustion Modeling-An Overview), Plenum Press, 1980, $1-38$

8. Heywood, J. B., Internal Combustion Engine Fundamentals, Mc-Graw Hill, 1987

9. Wylen, G. V.; Sonntag, R.; Borgnakke, C., Fundamentals of Classical Thermodynamics, Wiley, Fourth Edition, 1993

10. Cengel Y. A.; and Boles, M. A., An Engineering Approach Thermodynamics, McGrow Hill, Second Edition, 1994

11. Moran M. J.; Shapiro, H. N., Fundamentals of Engineering Thermodynamics, Wiley, Second Edition, 1993

12 Michaelides, E. E., Alternative Energy Sources (Green Energy and Technology), Springer, 2011

13. Guzzella, L.; Onder, C. H., Introduction to Modeling and Control of Internal Combustion Engine Systems, Springer, 2010 